DOI: $10.17805 /$ trudy.2015.3.5

\title{
СОВРЕМЕННАЯ ГОСУДАРСТВЕННАЯ КУЛЬТУРНАЯ ПОЛИТИКА РОССИИ И ПУТИ ЕЕ РЕАЛИЗАЦИИ В СФЕРЕ ПРОФЕССИОНАЛЬНОГО ОБРАЗОВАНИЯ
}

\author{
В. И. Колношенко, О. В. Колношенко \\ (Московский гуманитарный университет)
}

Аннотация: В статье анализируется сущность и задачи современной культурной политики России. Раскрывается новый подход к пониманию культуры, ее роли в современном обществе как источника развития. Дается характеристика целей и основных направлений реализации государственной культурной политики в различных сферах деятельности.

Ключевые слова: Основы государственной культурной политики, культурная политика, профессиональное образование, гуманизация профессионального образования.

\section{MODERN CULTURAL POLICY AND THE WAYS OF ITS REALIZATION}

\author{
V. I. Kolnoshenko, O. V. Kolnoshenko \\ (Moscow University for the Humanities)
}

Abstract: The article analyses the nature and tasks of modern cultural policy of Russia, exploring a new approach to understanding culture and its role in modern society as a driving force of development. We describe both the objectives and the main forms of implementing of State cultural policy in various fields of activity, especially in the sphere of higher education.

Keywords: culture, cultural policy, professional education, humanization of higher education, student-oriented approach.

В культурной жизни и деятельности российского общества в конце 2014 г. произошло важное событие - Указом Президента РФ от 24 декабря 2014 г. № 808 утверждены «Основы государственной культурной политики» (далее - Основы) (Утверждены Основы ..., 2014: Электр. ресурс).

Значение этого документа выходит за рамки сферы культуры, его влияние распространяется на все виды и структуры государственной деятельности, в том числе и в сфере профессионального образования. Предстоят этапы его изучения, анализа и практической реализации. Правильное понимание сущности концепции Основ государственной культурной 
политики является важным условием практической реализации поставленных в ней задач.

Прежде всего,важно учитывать, что в Основах сформулирована, по сути, новая концепция культуры и соответствующая ей государственная культурная политика.

Следует отметить также, что в науке культурологии не сложилось единого мнения о том, что считать культурой. Сегодня исследователи насчитывают более 500 определений этого понятия. Зачастую понятие «культура» трактуется либо слишком широко, либо «узко», односторонне (см.: Межуев, 2012).

Например, в некоторых странах Европы понятие «культура» является почти полным синонимом слова «искусство», и потому культурная политика государства направлена в основном на развитие изобразительного, музыкального и театрального искусства, литературы, на организацию фестивалей, дней искусств и т. п. (это «узкий» подход).

В 1990-е годы в России сформировался особый взгляд на культуру, в сущности, означающий «культурную деятельность», деятельность по оказанию культурных, главным образом, досуговых услуг (т. е. культура - это услуга). В действующем ныне Федеральном законе «Основы законодательства о культуре в РФ», отсутствует базовое понятие «культура».

При таком «рыночном» подходе роль культуры сводится к обслуживанию свободного времени людей и не предполагает активную, преобразующую и, главное, самостоятельную роль в обществе. Государство, фактически устраняется от непосредственного управления сферой культуры, приоритет отдается регулирующей роли рынка. В соответствии с этим рыночным принципом все определяет рыночная конъюнктура, выживают только те виды культуры и культурные услуги, которые востребованы рынком (т. е. пользуются спросом). Этот подход, как известно, соответствует либеральной рыночной модели развития общества и его экономики, которая была принята и реализована нашими либеральными реформаторами в 1990-е годы.

Приоритетом культурной политики государства, при такой модели, является государственная поддержка малообеспеченной социальной группы населения, обеспечение их доступа к культурным ценностям через специальные целевые культурные программы, бесплатный доступ в музеи, популяризация культуры на государственных теле- и радиоканалах и прочее (Постановление Правительства ..., 2012: Электр. ресурс).

Как показывает опыт реализации такой государственной политики в 1990-х годах, основанной на узко-рыночной модели развития культуры, такая государственная культурная политика не только не способствовала духовному развитию общества, его духовной мобилизации, более того, 
создала условия для возникновения ряда негативных, кризисных явлений. Эти кризисные проявления отмечены в Основах. Это:

- снижение интеллектуального и культурного уровня общества;

- девальвация общепризнанных ценностей и искажение ценностных ориентиров;

- рост агрессии и нетерпимости, проявления асоциального поведения;

•деформация исторической памяти, негативная оценка значительных периодов отечественной истории, распространение ложного представления об исторической отсталости России;

- атомизация общества - разрыв социальных связей (дружеских, семейных, соседских), рост индивидуализма, пренебрежения правами других.

Это последствия, а причины этих явлений, на наш взгляд, кроются в недооценке роли культуры, ошибочной модели ее функционирования и развития в обществе.

В современных условиях уже многие политики и деятели искусства, обратили внимание на несоответствие, ограниченность узко рыночного понимания роли культуры. Понимание активной и преобразующей роли культуры признано в ряде докладов ЮНЕСКО. Эти документы внесли свой вклад в подготовку современной концепции культуры как средства (базового фактора) развития общества.

В современном мире культура становится значимым ресурсом социально-экономического развития. Важным является то, что в Основах культура России приравнивается такому же ее достоянию, как и природные богатства: газ, нефть, золото и другие ресурсы индустриальной эпохи. Будущие мировые рынки - это рынки культурной индустрии. Экспорт и импорт культуры сегодня является прерогативой всех постиндустриальных стран. Россия стоит перед выбором: или она импортирует культурные ресурсы и продукты, или экспортирует их.

В новой концепции Государственной культурной политики понятие «культура» трактуется как «совокупность формальных и неформальных институтов, явлений и факторов, влияющих на сохранение, производство, трансляцию и распространение духовных ценностей (этических, эстетических, интеллектуальных, гражданских, правовых и т. д.)» (Утверждены Основы ..., 2014: Электр. ресурс).

В современной концепции культура выполняет роли:

- самодостаточной ценности, активно влияющей на качество жизни и результаты деятельности людей, залогом стабильного развития общества;

- значимого ресурса социально-экономического развития страны;

- важнейшего национального приоритета и фактора роста качества жизни и гармонизации общественных отношений; 
- гаранта сохранения единого культурного пространства и территориальной целостности России.

На основе понятия «культура» в документе дается развернутое определение понятия «государственная культурная политика» и формулируются его задачи в различных областях деятельности.

Культурная политика трактуется в документе как «практические действия, осуществляемые органами государственной власти Российской Федерации и общественными институтами, направленные на поддержку, сохранение и развитие всех отраслей культуры, всех видов творческой деятельности граждан России и формирование личности на основе присущей российскому обществу системы ценностей» (там же).

Из данного определения вытекает, что ключевой целью современной государственной культурной политики является развитие личности человека средствами культуры на основе присущей российскому обществу системы ценностей.

Основы государственной культурной политики определяют:

• главные направления культурной политики;

- представляют собой базовый документ для разработки и совершенствования законодательных и иных нормативных правовых актов Российской Федерации, регулирующих процессы культурного развития в Российской Федерации, а также государственных и муниципальных программ;

• определяют цели и стратегические задачи государственной культурной политики, ключевые принципы ее реализации.

- приоритетное культурное и гуманитарное развитие как основу экономического процветания, государственного суверенитета и цивилизационной самобытности страны.

- основы стратегии национальной безопасности РФ.

Важным объектом реализации государственной культурной политики является сфера профессионального образования.

Организация деятельности учебных учреждений в этой сфере, как известно, осуществляется на основе Федерального закона РФ от 29.12. 2012г. «Об образовании в РФ». Однако, учитывая принятие Указом Президента РФ «Основ государственной культурной политики», в их деятельности сегодня необходима корректировка образовательных целей и задач. Это обусловлено тем, что Основы представляют собой базовый документ для разработки и совершенствования законодательных и иных нормативных правовых актов Российской Федерации, они призваны регулировать все сферы и процессы культурного развития страны.

Главной стратегической целью государственной культурной политики в сфере профессионального образования, на наш взгляд, должно стать формирование духовных (образовательных, моральных, эстетических, художественных и др.) качеств личности учащихся, организация и непо- 
средственное проведение системной культурно-просветительной и воспитательной работы с ними.

Для достижения этой цели государственная культурная политика ориентирует на решение следующих стратегических задач:

1) приоритетное развитие гуманитарных наук, как наук о человеке, его духовной, нравственной, культурной и общественной деятельности;

2) проведение необходимых фундаментальных и прикладных исследований в сфере гуманитарных наук;

3) повышение качества подготовки научных и научно-педагогических кадров в сфере гуманитарных наук.

Здесь чрезвычайно важна образовательная деятельность вузов. В этой связи учебные заведения обязаны ставить перед собой задачу готовить не просто компетентных высококвалифицированных специалистов, но и людей высокой культуры и нравственности, имеющих научное мировоззрение, способных к деятельности в условиях конкуренции, умеющих ориентироваться в потоке научно-технической информации, работать с технической литературой, осваивать новые технологии, ориентироваться в современных рыночных условиях, постоянно повышать квалификацию.

Наиболее полно соответствует этим задачам гуманистическая концепция обучения и воспитания, так как она создает оптимальные условия для раскрытия, коррекции и развития личности студента. А коммуникативнодеятельный подход, как показала практика, дает возможность использовать естественную потребность студента в самовыражении, опирается на реализацию стремления человека к общению с окружающим миром.

В основе профессионального образования должна лежать концепция гуманизации образования, формирования целостной личности как субъекта культуры, развитие у человека тех личностных качеств, которые дают ему возможность самостоятельно ориентироваться в области профессиональных и естественнонаучных знаний, то есть способностей, наиболее востребованных в современном обществе.

Любое учебное учреждение, в т. ч. вузы, поставившее своей целью обучение конкурентно способных специалистов, должны усилить внимание к повышению качества преподавания дисциплин гуманитарного цикла: философии, психологии, истории, культурологии, русского и иностранных языков и др. В изучении гуманитарных дисциплин важно практически решать задачу по развитию свободной личности, ее культурного и нравственного формирования.

Актуальными, на наш взгляд, становятся задачи по внедрению личностно-ориентированного подхода в профессиональном образовании, совершенствования обучения и воспитания студентовсредствами современных педагогических технологий. Вариантами такой технологии могли бы стать ранее предложенные авторами технологии педагогического, соци- 
окультурного менеджмента (Колношенко В., Колношенко О., 2013, 2014).

Основными направлениями реализации задач государственной культурной политики в образовательной деятельности вуза должны стать следующие.

Во-первых, корректировка содержания научно-исследовательской работы кафедр гуманитарного профиля, проведение необходимых фундаментальных и прикладных исследований в сфере гуманитарных наук, реализации актуальных проблем государственной культурной политики.

Решая эту задачу, кафедры вузов могут использовать разнообразные формы научно-исследовательской и методической работы: защита кандидатских, докторских, диссертаций, посвященных исследованиям проблем в сфере культуры и культурно-досуговой деятельности учреждений культуры; научные исследования в форме дипломных работ, магистерских диссертаций студентов; публикация учебников, учебных и учебнометодических пособий, научных статей и др.

Важными направлениями научного исследования в области гуманитарных наук, на наш взгляд, могут стать:

- проблемы гуманизации общего и профессионального образования;

• повышение качества владения гражданами России русским языком, использование эталонного русского литературного языка;

•утверждение в общественном сознании традиционных культурных, этических и эстетических ценностей;

•деятельность государственных, общественных, общественногосударственных институтов в распространении среди граждан знаний и культуры;

- развитие детского и молодежного движения, ориентированного на творческую, добровольческую, благотворительную, познавательную деятельность;

- формирование информационной грамотности граждан;

- комплексное совершенствование системы управления сферой культуры, обеспечению реализации и мониторингу достижения целей государственной культурной политики;

- аналитическое и информационное обеспечение разработки и реализации государственной культурной политики;

•повышение качества подготовки научных и научно-педагогических кадров в сфере гуманитарных наук.

Во-вторых, актуальной задачей по реализации государственной культурной политики в современном вузе становится активизация использования форм и методов культурно-просветительной и культурнодосуговой работы со студентами, формирование у обучаемых общей культуры и системы культурных ценностей.

Как уже отмечалось, современное профессиональное образование 48 
обязательно предполагает общекультурный компонент. В этой связи требуется коррекция содержания образовательных программ с учетом требований «Основ государственной культурной политики». В частности, в образовательном процессе важно развивать у студентов потенциал общей культуры, приобщать их к лучшим произведениям отечественной и мировой культуры. В решении этой задачи следует шире использовать возможности учреждений культуры г. Москвы, практиковать регулярное посещение студентами музеев, театров, выставок изобразительного искусства, концертов мастеров музыки, танца и других культурных мероприятий.

B-третьих, в образовательной деятельности вуза важное место должна занимать работа по развитию художественного творчества и самодеятельности среди студентов во внеучебное время.

Как отмечается в «Основах государственной культурной политики» ее целью является развитие личности, творческих способностей человека. В этой связи в вузе важно реально обеспечить условия для развития художественного творчества студентов, функционированияразнообразных кружков, любительских и творческих объединений.

Таким образом, анализ положений «Основ государственной культурной политики», содержания его основных идей позволяет сделать ряд методологически важных выводов:

1) в современных условиях культура рассматривается как неотъемлемый и относительно самостоятельный компонент жизнедеятельности общества и выражает собой интеллектуальный уровень его развития на разных ступенях его социальной зрелости. Культура и культурная деятельность становятся приоритетом государственной культурной политики,

2) важным направлением реализации государственной культурной политики является сфера профессионального образования, основной целью и задачей которой является не подготовка обучаемых не только как будущих специалистов, но и как человека, духовно обогащенной личности.

\section{СПИСОК ЛИТЕРАТУРЫ}

Межуев, В. М. (2012) Идея культуры. Очерки по философии культуры. М. : Университетская книга.

Колношенко, В. И., Колношенко, О. В. (2013) Проблема оценки эффективности педагогического менеджмента образовательного процесса в вузе // Научные труды Московского гуманитарного университета. № 11 . C. $60-71$.

Колношенко, В. И., Колношенко, О. В. (2014) Социокультурный менеджмент: сущность и специфика // Научные труды Московского гуманитарного университета. № 3. С. 59-69.

Утверждены Основы государственной культурной политики (2014) 
[Электронный ресурс] // Президент России. Официальный сайт. 24 декабря. URL: http://www.kremlin.ru/events/president/news/47325 (дата обращения: 13.03.2015).

Постановление Правительства Российской Федерации от 3 марта 2012 г. № 186 О Федеральной целевой программе «Культура России (2012-2018 годы)» (2012) [Электронный ресурс] // Министерство культуры PФ. URL: http:// http://fcpkultura.ru/docs.php?id=53 (дата обращения: 12.04.2015).

Колношенко Владимир Иванович - кандидат исторических наук, доцент кафедры менеджмента Московского гуманитарного университета, доцент, заслуженный работник культуры РФ. Адрес: 111395, Россия, г. Москва, ул. Юности, д. 5. Тел.: +7 (499) 374-70-13. Эл. адрес: kaf.76@mail.ru

Колношенко Олег Владимирович - кандидат педагогических наук, доцент кафедры менеджмента Московского гуманитарного университета доцент. Адрес: 111395, Россия, г. Москва, ул. Юности, д. 5. Тел.: +7 (499) 374-70-13.Эл. адрес: kaf.76@mail.ru

Kolnoshenko Vladimir Ivanovich, Candidate of History, Associate Professor, Department of management, Moscow University for the Humanities, Honored Worker of Culture of the Russian Federation. Postal address: 5 Yunosti St., 111395 Moscow, Russian Federation. Tel.: +7 (499) 374-70-13. E-mail: kaf.76@mail.ru

Kolnoshenko Oleg Vladimirovich, Candidate of Pedagogy, Associate professor, Department of management, Moscow University for the Humanities. Postal address: 5 Yunosti St., 111395 Moscow, Russian Federation. Tel.: +7 (499) 374-70-13.E-mail:kaf.76@mail.ru 